\title{
Management Innovation for SMEs Based on Internet Thinking
}

\author{
Li-Hua Wang* \\ Business school of China West Normal University Nanchong city, Sichuan Province, China \\ 313153290@qq.com \\ ${ }^{*}$ Corresponding author
}

Keywords: Internet thinking, SMEs, Management innovation.

\begin{abstract}
Based on the impact of existing Internet thinking, analyzing the current development of SMEs, the enterprise proposed to adapt to future innovation and social development must be managed. Through literature retrieval methods, management innovation analyzed from five aspects, while the value of a user-centric proposed three-tier structure of the ring thinking, from five areas of innovation analysis based on this thinking.
\end{abstract}

\section{Introduction}

E-commerce has changed our lives, not only to expand the original network marketing sales area, as well as the development of enterprises to provide a lot of opportunities. After an investigation found that many business e-commerce is the main mode "+ Internet" form, which is mainly the original sales model to increase Internet sales platform, this model is really a short term increase in the sales volume for the enterprise. In the long run the limitations of this model stand out slowly, companies need a new business model to create new value.

The third session of the 12th National People's Congress (NPC), Premier Li Keqiang in his government work report first proposed the "Internet + " plan of action. The action plan is the traditional business and e-commerce development of a new stage. "Internet + " of thinking is to carry out all the activities of companies on the Internet platform, such as design, production and sales, and so on. In such a new era of SMEs have to be adapted to the times through management innovation, so that enterprises Everlasting.

\section{Theoretical overview}

SMEs (Small and Medium Enterprises), also known as the small and medium enterprises, or SMEs, these companies often can be a single person or a few people to provide funds, whose number of people employed and turnover size is not large, so the business is mostly made direct management of the owners, is less affected by outside interference. China's SMEs account for over $98 \%$ of the total number of enterprises, the contribution of new jobs was $85 \%, 60 \%$ GDP, and $50 \%$ of revenue, so whether it is employment or innovation, or in economic development has a very important role [1]. Internet thinking is at (mobile) internet, big data, cloud computing and other technology evolving background, market, customers, products and business value chain as well as to carry out the entire business ecosystem to re-examine ways of thinking [2]. Zhou Hongyi, chairman of 360 company First proposed the Internet thinking the Internet thinking first proposed, to promote "customer first, experience is king, single point of breakthrough, subversive innovation" This 16-word mantra. This concept is now gradually being recognized by more and more entrepreneurs.

Management innovation is the corporate management of the new features (such as new management methods, new management tools, new management mode, etc.) or a combination of elements into a business management system to more effectively achieve organizational objectives behavior. 


\section{Management situation of SMEs}

\section{Traditional SMES have realized the need to adapt to the new era of innovation}

The total number of SMEs in the country has reached more than 40 million, but the average life expectancy less than three years and there is a downward trend. The industry due to the large number of enterprises, more and more intense competition among enterprises; on the other hand, the government in order to solve the problem of employment, encouraging entrepreneurship, which exacerbated the competitiveness of enterprises. In this tough competitive environment, companies must be managed in order to avoid being eliminated innovation. Repeated success of e-commerce has become the talk of the business focus. Taobao.com high-profile business, the annual Singles marketing activities. Data from the Ali Group show, only one day's turnover of 100 million Yuan from 2009 rose to 57.1 billion in 2014, just five years, but its growth rate is staggering. Data as shown in figure 1 . Taobao.com these benefits, it is built on the foundation of the Internet on the results of innovation. As traditional SMEs already seen, this favorable situation, enterprises need to innovate to create new revenue growth.

2009--2014 Taobao. com Double 11 promotion sales

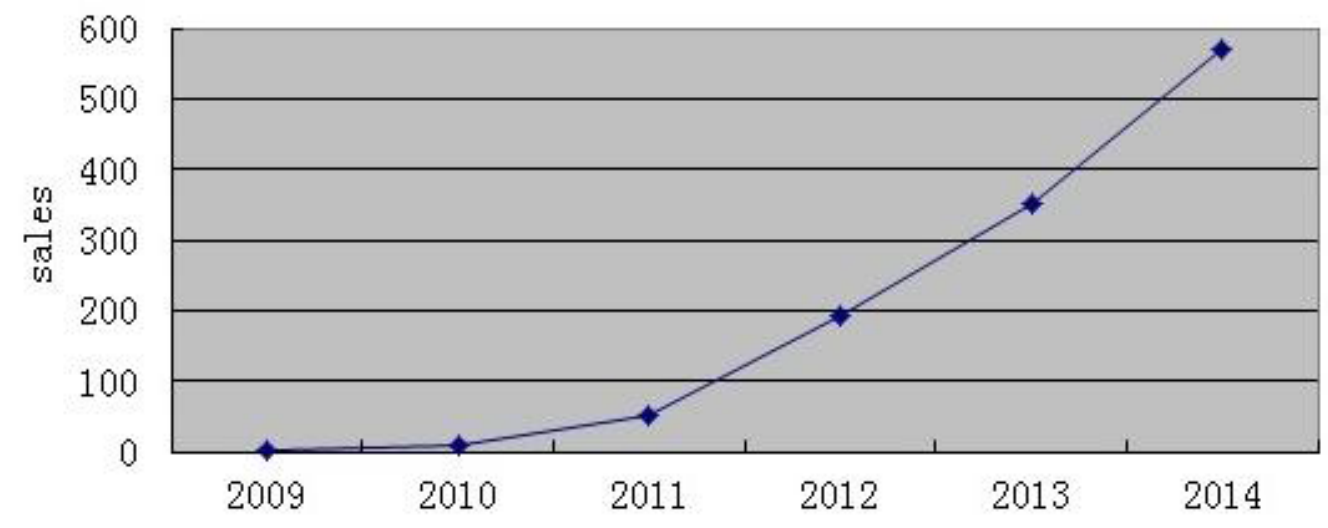

Fig.1 2009--2014 Taobao Double 11 promotional sales

\section{SMEs will face a crisis and panic transition being eliminated}

Due to the characteristics of SMEs themselves are small and therefore its transformation fast and strong adaptability, SMEs easier to implement management innovation. Internet on traditional business applications will become deep level challenge traditional industries, in-depth application in the form of not only more colorful, more expensive in cost, of course, inexpensive items sought after by others. As Tencent micro-channel communications software on the Internet can easily transfer various forms of text information, such as sound, image and even small video and other information. WIFI environment as long as there are free to pass this information. Tencent used only by the business less than three years to subvert the reason Telecom, China Mobile and China Unicom three major state-owned telecommunications companies in operation for a number of years of SMS. Another is the case of Internet access to financial services such as payment of the balance of Bao Bao business in the short term on the financing of hundreds of billions of funds, due to the strict control of risk so the state lowered its rate of return and risk. Although it is now it does not have the appeal of high-yield, because of its small sums of money to access / transfer easy and free features, more and more people as the storage / retrieval Preferred / rev paragraph. The business is based on an innovative new Internet business, banking institutions if not timely transition, presumably after their presence will gradually replace the traditional banking business. If the Internet and all the traditional sectors combined with innovative mesh networking era will bring new page. Traditional SMEs in this environment, if not timely transition or unsuccessful transition will be eliminated by the times. 


\section{Traditional SMEs existing resources to become an innovation bottleneck}

First, companies lack of human resources on the Internet thinking. A few years ago, having been aware of the e-commerce can provide a greater sales volume and revenue, but did not realize the attendant thought the Internet would make people's work and life changed dramatically, so in recruitment aspect has not been involved in this area of recruitment. Because of past employees accustomed to the original mode, so they change a mindset, is the need to accumulate a certain period of time and knowledge. Second, the lack of internal information systems. Although many SMEs affected by the traditional business channels, revenue growth in recent years, mainly on the scale, such as the opening of a new factory, adding new items. Points of view but many SMEs do not have its strengths, which is not only large and stronger. Transmission of information within the enterprise is still the traditional way, no build suitable enterprises own information systems. Traditional management communication, already cannot adapt to the Internet era a lot, high speed transmission of information, of course, this is becoming a bottleneck thinking businesses build Internet. Again, the lack of rational management system and mechanism. Lack of management systems for SMEs, especially in the employment context the lack of development of relevant institutions to restrain and motivate employees, usually humane management, and lack of rigorous systematic management approach. Humane management style, to a certain extent, can fully mobilize the enthusiasm of the staff, but the longer the duration, the manager will feel heavier the burden. The above three points belong to a number of issues in the SME management on three main issues; also this paper is to analyze the main problems to solve.

\section{Corporate management and innovation to achieve path}

\section{Customer of Internet-based products midpoint redefined}

Based on Dawei Zhao's research result, the authors propose a new concept of the value of the ring .Internet thinking first and foremost thing is customer-oriented perspective. And strive to achieve customer-centric, conduct research and design, material procurement, production, sales and after-sales network feedback products, as shown in Figure 2.

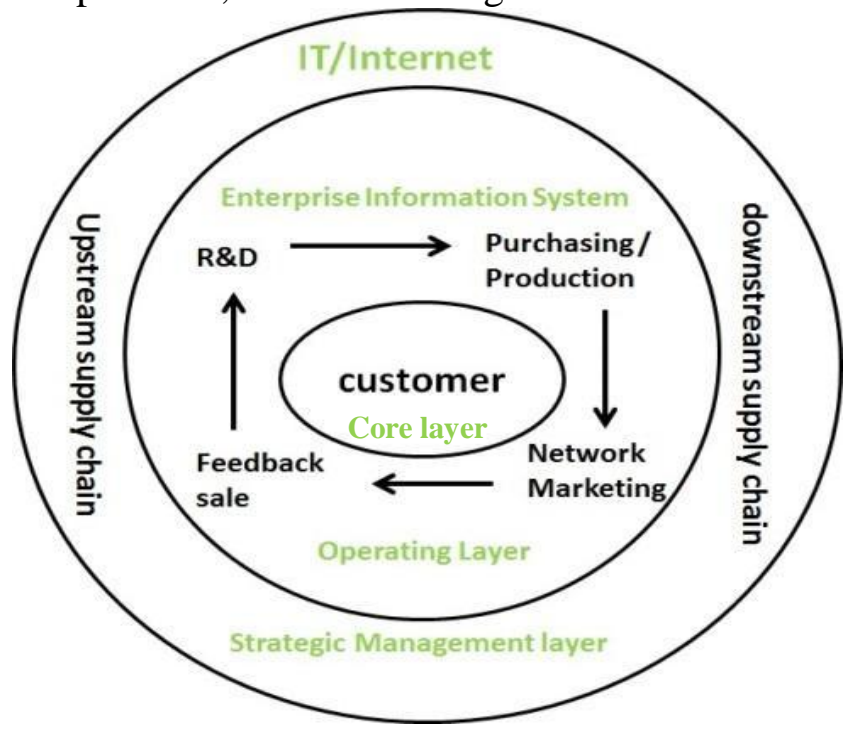

Fig.2 Enterprise Management Innovation Value ring

The customer in the core layer that reflects the customer-centric thinking. The outer layer is an operation layer is operating. This layer is a key link in enterprise management information system, customer information systems through product customization, raw material procurement and production, to generate sales information and after-sales feedback information gathering. The outermost layer of the corporate strategy, this one based on the Internet and IT technology to extend enterprise management information system functions, and with partners in the supply chain for 
timely information and communication. Internet users can achieve this environment customized production, personalized needs of users. SMEs in such an environment, establish a good, long-term customer relationships is especially important by creating a database to record information about the customer, the database has a long-term preservation of function, allowing companies to maintain relations targeted. Traditional Chinese SMEs actually experience the brand at the same time and to the process of branding, this is a process of unity of opposites. In this environment, the Internet should have the courage to remove some of the features of the original brand, re-re-branding on the Internet platform based on the user's needs and characteristics of the product itself.

\section{Brand \& channel \& talent business model}

Internet-based network to the user to create brand-centric, not only reflects its own characteristics, but also reflects the innovative spirit of the times. SMEs in the Internet platform, and large enterprises have the same audience crowd, speaking from corporate strength, and big business is not having a positive financial resources to compete, but SMEs can take the form of flanking warfare, one aspect of the prominent features of products create a unique brand, thereby locking the relevant customer base, ultimately to gain a foothold. On the Internet-based platform for supply chain can achieve effective management. Fast, interactive and other knowledge sharing and staff constitute the elements of effective information management. In the Internet environment, companies no longer compete with companies like the individual and the individual competition in the past, but rather showing a competitive supply chain and supply chain. Competition in the supply chain is no longer a cut-throat competition as in the past, but a competing relationship, both under certain conditions a competitor, when itself does not have a certain condition, but when you have to resort to other people is a partnership, so the age of the Internet among enterprises and enterprises where there was a strong competing relationship. Two important factors in addition to brand and channel, human resources is a major core elements. Internet culture thinking echelon personnel is very important to the development of an enterprise depends mainly on the composition of human resources. Talents Internet era, IT skills and Internet knowledge is basic common sense, combined with the Internet expertise of thinking is coming new talent. SMEs in a transition period, human resources constitute can be achieved in two ways. On the one hand the introduction of new Internet talent, on the other hand, the existing human resources training Internet thinking, enables construction-related human resources.

\section{Innovative business experience \& free model}

Another key feature of the Internet thinking is the user experience and free opportunity. You get to experience the benefits of the product by the opportunity to experience the process, in this process, users of the products have certain affection and even the formation of some kind of dependence, this dependence is additional products or services provided to create conditions late. Enterprises through this dependence make some kind of post-consumer product sales model, long-term benefit from this sales model. SMEs according to their product features, innovative products sales model, the main products to be sold at an affordable price, and later additional products and services are targeted at price contains certain sales profits. HP printers such as the price is very cheap hosting, do not make money, but the price of its consumables such as ink cartridges is very expensive special, through the sale of the latter part of the ink cartridge to the final profit initially give users the opportunity to experience a free, user at this opportunity inside to receive benefits, the latter will continue to buy, companies committed to innovation and value-added marketing services late, neither let it irreplaceable, letting the user feel very loved.

\section{The application of information system construction and data processing technology}

SMEs in their own infinite expansion, the system does not pay attention to the construction of information technology, perhaps some companies have created information technology, but the lack of ongoing maintenance and reasonable use of such information systems companies which exist in name only, not much practical value. If the efficiency of the Internet era and enterprise internal and external information transmission speed uncoordinated, then the business before the Internet can be 
prohibitive. With the rapid development of information technology and network technology, enterprises need to establish a sound internal information system in order to achieve office automation. Because of the characteristics of SMEs themselves are small, lack of funds, according to the law of development Nolan model, determining information system development phase, to create their own information systems by way of purchase, so that both reduces development time, but also reduces maintenance costs later. Big Data era is coming, small and medium enterprises in this transition period, but also should pay attention to the collection and processing of data, especially to deal with this part of the data, through a lot of historical data analysis to provide a more reliable basis for making management decisions to do the right decisions. Simon once said: "Management is decision making" visible the right decisions for the right management. Supply chain can be obtained correlation between the product and product data through horizontal analysis to develop more effective sales strategies. Big data era, companies must do proper collection and processing of data, it can be more effective.

\section{Organizational structure and business processes based on recombinant Internet thinking}

On the Internet platform, enterprises in order to adapt to the rapid response process orders, it must take the enterprise had a vertical pyramid structure into a flat type linear structure, thus reducing the time information transfer, can respond faster. At the same department information transfer less, also reduces the error rate during transmission, thus improving the accuracy of decisions. Information systems and organizational structures of enterprises established should adapt, that is, to develop information systems strategy based on business strategy. According to the function of the organizational structure for process reorganization, division information function module structure on the basis of the reorganization, both for information systems operation and maintenance, but also to facilitate business in time to receive information and make decisions.

\section{Conclusions}

In the era of rapid development of information technology, the traditional SMEs to adapt to the development of society, we must make the transformation; the transition will be achieved through management innovation. This transformation of the enterprise itself is both a challenge and an opportunity. Challenge is the corporate restructuring is not successful if it will face the possibility of elimination, so there is a big risk, it has a great challenge. Opportunity means that if the transition is successful, that is adapted to the development of the times, and then the enterprises themselves, there will be great progress. But the management of innovation should be thorough, disruptive innovation. SMEs must seize the opportunity to do a full analysis, obtained late development through management innovation can. Article confined space reasons; there are many issues that need more in-depth analysis, which is the direction I would later study.

\section{References}

[1] Information on http://baike.baidu.com.

[2] Information on http://baike.haosou.com/doc/7488708-7759244.html. 